\title{
GT2018-77059
}

\section{TEMPERATURE DEPENDENCE OF CRACK GROWTH UNDER LCF FOR DIFFERENT ALLOYS}

\author{
S. Rabbolini \\ Department of Turbine Design \\ Exergy ORC \\ Olgiate Olona, Italy 21057 \\ Email: s.rabbolini@exergy.it
}

\author{
S. Foletti \\ Department of Mechanical Engineering \\ Politecnico di Milano \\ Milan, Italy 20156 \\ Email: stefano.foletti@polimi.it
}

\author{
S. Beretta \\ Department of Mechanical Engineering \\ Politecnico di Milano \\ Milan, Italy 20156 \\ Email: stefano.beretta@polimi.it
}

\begin{abstract}
Fatigue crack growth in plastic regions is one of the main factors for life assessment of components subjected to plastic strains. Residual life can be evaluated considering a crack growing from component first load cycle, considering an appropriate crack growth model. The aim of this work is to discuss the effects of temperature on crack propagation during low cycle fatigue. In particular, a series of experiments at high temperature (up to $T=700^{\circ} \mathrm{C}$ ) were performed on a Ni-based superalloy, to determine crack growth rates in the LCF regime. During tests interruptions, crack growth was measured using the plastic replica technique. Experimental results were examined in terms of crack growth rates and a model based on elastic-plastic J-Integral. Results showed that at high temperature there is a significant increase of crack growth rates respect to models usually valid at room temperature.
\end{abstract}

\section{NOMENCLATURE}

$a$ Crack length.

$a_{0}$ Initial crack length.

$a_{f} \quad$ Crack length to failure.

$c, m$ Paris Law constants.

$d a / d N \quad$ Crack growth rate.

$f\left(n_{i}\right) \quad$ Function for plastic J-Integral range description.

$n_{i} \quad$ Cyclic strain/stress curve exponent.

E Young's modulus.
$\mathrm{R}_{\mathcal{E}} \quad$ Strain ratio $\left(\varepsilon_{\min } / \varepsilon_{\max }\right)$.

$\mathrm{R}_{\sigma}$ Stress ratio $\left(\sigma_{\min } / \sigma_{\max }\right)$.

$\mathrm{R}_{m} \quad$ Ultimate tensile strength.

$\mathrm{R}_{p, 0.2 \%}$ Yield stress.

Y Geometrical Factor.

$\Delta J_{\text {eff }} \quad$ Effective J-Integral range.

$\Delta W_{e, e f f} \quad$ Effective elastic strain energy density.

$\Delta W_{p, e f f} \quad$ Effective plastic strain energy density.

$\Delta \sigma_{e f f} \quad$ Effective stress range.

$\Delta \varepsilon_{e f f} \quad$ Effective strain range.

$\Delta \varepsilon_{p, e f f} \quad$ Effective plastic strain range.

$\sigma_{0} \quad$ Flow stress.

$\sigma_{\max }$ Maximum stress during the fatigue cycle.

$\sigma_{\text {close }}$ Crack closing stress.

$\sigma_{o p e n}$ Crack opening stress.

$v$ Poisson's ratio.

\section{INTRODUCTION}

Turbine rotating components, such as rotors and disks, are designed to withstand the cyclic loads induced by centrifugal forces and by differential temperatures during startups and shutdowns. An important factor in massive components design is the presence of defects (inclusions, inhomogeneities, ..), which can strongly reduce operational life, which is usually assessed by turbine manufacturers with isothermal Low Cycle Fatigue (LCF) design curves [1]. 
Fatigue life assessment of disks and rotors subjected to LCF loads can be estimated considering a crack propagation problem, in which the crack starts propagating from the first load cycle, together with an appropriate crack growth model [2]. Crack growth rates in the LCF regime are usually described with the model based on the cyclic J-Integral, $\Delta J$, originally proposed by Dowling [3]. Several applications of $\Delta J$ models on LCF crack growth can be found in the literature [4-7].

Plasticity induced crack closure plays an important role even in LCF propagation. Crack closure effects were investigated and introduced in $\Delta J$ models in the works of McClung and Sehitoglu [8,9] together with those of Seeger and Vormwald $[10,11]$. $\Delta J$ equation was modified by reducing stress and plastic strain ranges, considering only the part of the fatigue cycle in which the crack stays open. It was shown that crack opening levels corresponded to those calculated adopting the model proposed by Newman [12] for long cracks, where the opening stress for a given strain ratio depends on the constraint factor and the ratio $\sigma_{\max } / \sigma_{0}$.

In this paper the application of $\Delta J$ models to Haynes 230, a Ni-based superalloy, is discussed. In particular, an experimental campaign on micro-notched specimens at high temperature (up to $700^{\circ} \mathrm{C}$ ) was developed. Crack growth rates were correlated with the external applied load with a model based on $\Delta J$. Experimental results showed that at high temperature there is a significant acceleration of short crack growth rates respect to crack growth models valid at room, confirming the observations reported in [13], in which it was shown that this speed increment is temperature dependent.

\section{EXPERIMENTS}

An experimental campaign was developed to study short crack propagation on Haynes 230. this is a Ni-based superalloy, employed for high temperature applications, such as gas turbine combustors, since it exhibits good resistance at creep and corrosion. Specimens employed for testing were obtained from a 38 $\mathrm{mm}$-wide round bar, whose chemical composition is reported in Table 1.

TABLE 1. CHEMICAL COMPOSITION (\%WT) OF HAYNES 230.

\begin{tabular}{cccccccc}
\hline $\mathrm{Al}$ & $\mathrm{B}$ & $\mathrm{C}$ & $\mathrm{Co}$ & $\mathrm{Cr}$ & $\mathrm{Cu}$ & $\mathrm{Fe}$ & $\mathrm{La}$ \\
0.35 & 0.005 & 0.1 & 0.16 & 22.14 & 0.04 & 1.14 & 0.015 \\
\hline $\mathrm{Mn}$ & $\mathrm{Mo}$ & $\mathrm{Ni}$ & $\mathrm{P}$ & $\mathrm{S}$ & $\mathrm{Si}$ & $\mathrm{Ti}$ & $\mathrm{W}$ \\
0.5 & 1.25 & $\mathrm{Bal}$. & 0.005 & 0.002 & 0.49 & 0.01 & 14.25 \\
\hline $\mathrm{Zr}$ & & & & & & & \\
0.01 & & & & & & & \\
\hline
\end{tabular}

Two different temperatures were investigated: initially, the superalloy was tested at $500^{\circ} \mathrm{C}$, in order to compare experimental results with those obtained testing a quenched and tempered steel [13]. The second experimental campaign was carried out at $700^{\circ} \mathrm{C}$, a typical Haynes 230 working condition.

For each temperature, three different categories of experiments were performed. Initially, $6 \mathrm{~mm}$ wide cylindrical specimens were monotonically loaded to evaluate Haynes 230 tensile properties. A summary of Haynes 230 tensile properties is reported in Tab. 2.

TABLE 2. HAYNES 230 TENSILE PROPERTIES.

\begin{tabular}{cccc} 
T & Young's & Yield & Ultimate tensile \\
& modulus, & stress, & strength, \\
{$\left[{ }^{\circ} \mathrm{C}\right]$} & $\mathrm{E}[\mathrm{GPa}]$ & $R_{p, 0.2 \%}[\mathrm{MPa}]$ & $R_{m}[\mathrm{MPa}]$ \\
& & & \\
\hline 500 & 166.9 & 350.6 & 789.5 \\
700 & 147.2 & 324.4 & 586.3 \\
\hline
\end{tabular}

In the second series of experiments, cylindrical specimens with a diameter of $8 \mathrm{~mm}$ and a gauge length of $20 \mathrm{~mm}$ were tested under constant strain amplitude loading at two different amplitude levels, with a fixed strain ratio $\mathrm{R}_{\varepsilon}=-1$. LCF tests were carried out at a frequency of $0.5 \mathrm{~Hz}$, using a MTS 810 servohydraulic testing machine. Experiments were performed with an high temperature longitudinal extensometer with a $12 \mathrm{~mm}$ long gage and temperature was obtained with induction heating: during the experiments, 5 thermocouples controlled the applied temperature on the specimen surface. In Fig. 1a, the experimental setup for LCF high temperature testing is shown.

Each specimen contained an artificial semicircular micronotch, obtained by Electrical Discharge Machining (EDM): 400 $\mu m$ depth notches were employed in this phase. A schematic of the specimen employed for testing is reported in Fig. 1b, in which notch orientation is also shown.

During the experiments, crack advancement was measured, after fatigue tests interruption, using the plastic replicas technique with a thin acetate foil. An example of a so-obtained replica at $500^{\circ} \mathrm{C}$ is presented in Fig. 1c, in which crack propagation can be observed on specimen surface starting from the artificial defect. During the analysis, it was assumed that cracks propagated maintaining a semi-circular crack-front: this assumption was validated after the end of the tests, when specimens, broken in liquid nitrogen, exhibited a semicircular fatigue crack. Experimental crack length were employed to calculate crack growth rates, $d a / d N$, by the secant method and models parameters calculation was based on these growth rate data, reported in Fig. 


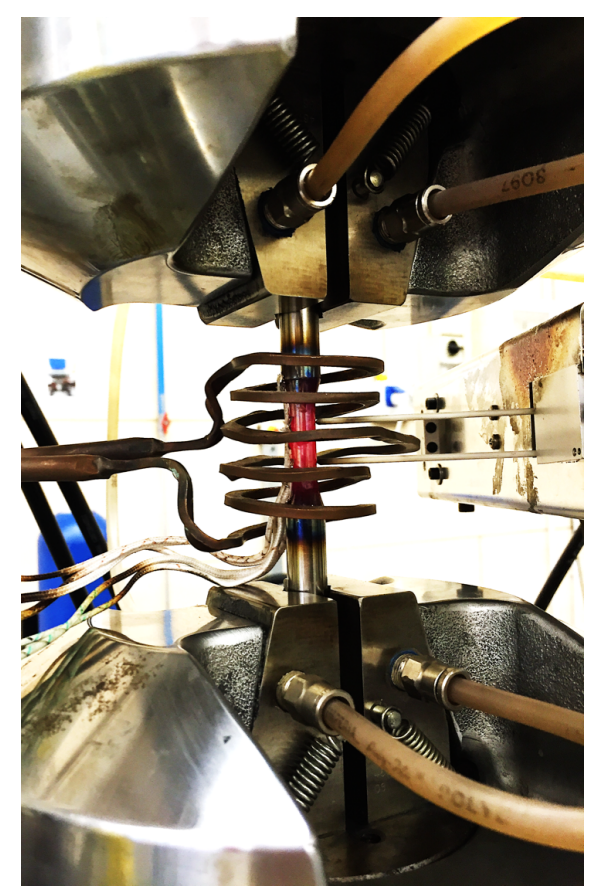

(a)

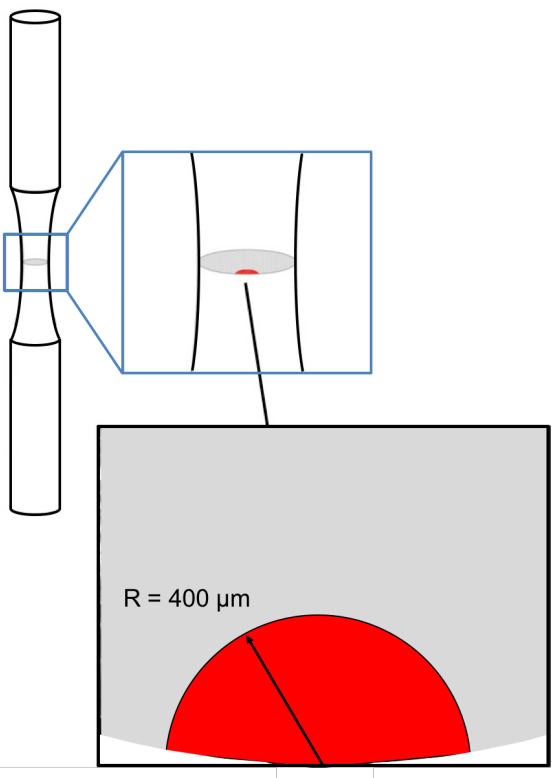

(b)

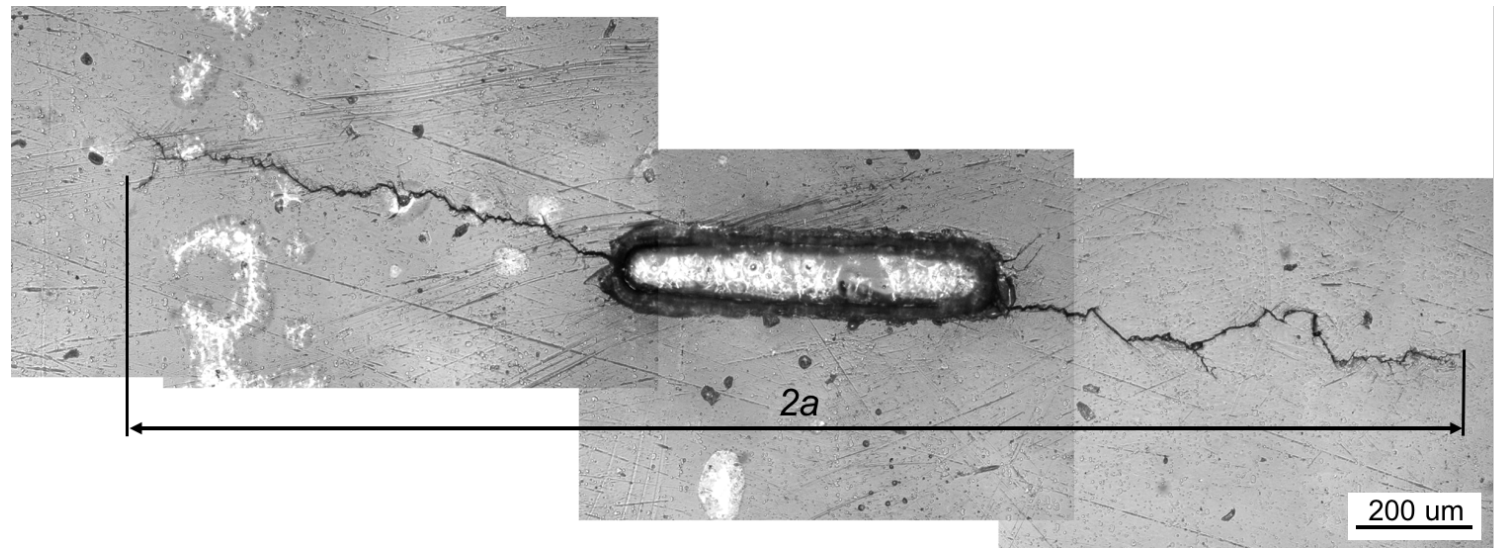

(c)

FIGURE 1. LCF testing at high temperature: a) Experimental setup for high temperature LCF testing $\left(\mathrm{T}=700^{\circ} \mathrm{C}\right)$, b) Specimen geometry and notch orientation and c) surface crack propagation observed on a plastic replica, $\mathrm{T}=500^{\circ} \mathrm{C}$.

2.

The third series of experiments was performed to obtain reference $d a / d N-\Delta K_{e f f}$ curves. Tests were carried out on 0.5 inch compact tension $(\mathrm{C}(\mathrm{T}))$ specimens, following the constant amplitude (CA) procedure proposed in the ASTM E647 standard. A load ratio $\mathrm{R}_{\sigma}$ equal to 0.7 was deemed necessary, to obtain closure-free propagation curves. During all the experiments, the load frequency was fixed at $0.5 \mathrm{~Hz}$, the same frequency adopted for LCF testing.

\section{CRACK GROWTH ANALYSIS}

Experimental results were analyzed with the model based on the effective cyclic J-integral range, $\Delta J_{e f f}[8,10]$, which accounts for both inelastic strains and crack closure. $\Delta J_{e f f}$ is a function of $\Delta W_{e, e f f}$ and $\Delta W_{p, e f f}$, the effective elastic and plastic strain energy densities [13]. These quantities can be extracted from the remote stress/strain loop, considering only the part of the fatigue cycle in which the crack stays open, as depicted in Fig. 3 and reported in Eq. 1 [13], in which $a$ is the crack length, $Y$ is the geometric factor that accounts for crack geometry, $v$ is 


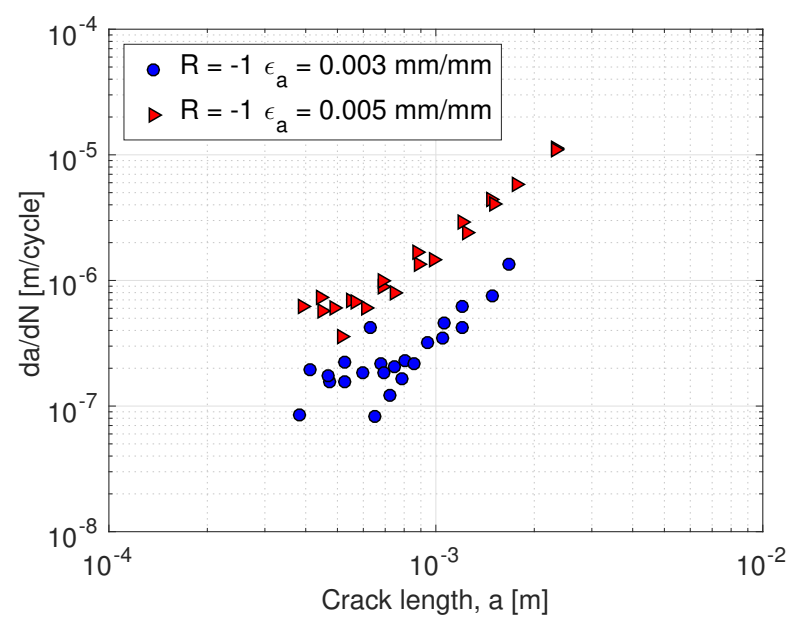

(a)

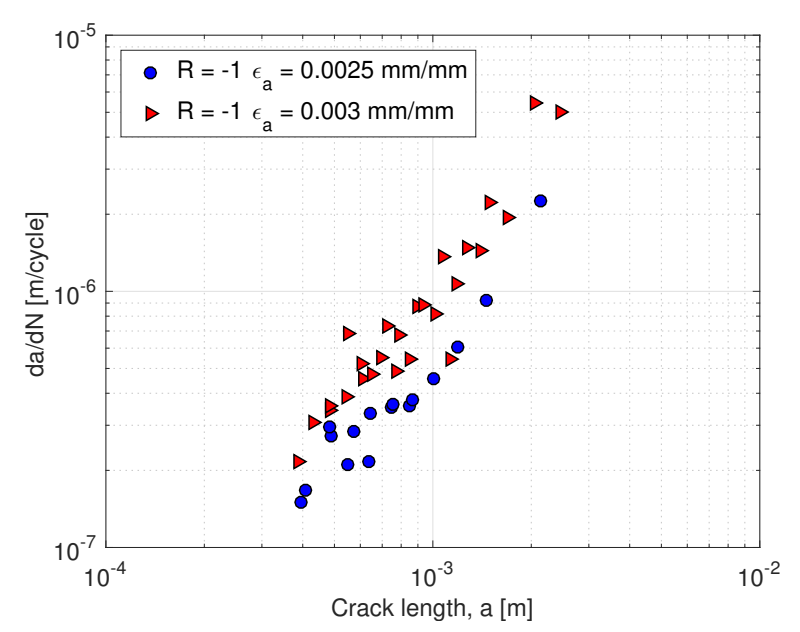

(b)

FIGURE 2. Crack growth results, LCF tests: a) $\mathrm{T}=500^{\circ} \mathrm{C}$, b) $\mathrm{T}=700^{\circ} \mathrm{C}$.

the Poisson's ratio and $f\left(n_{i}\right)$ is a function that considers material elastic-plastic behavior.

$$
\Delta J_{e f f}=2 \pi Y^{2} a\left[\left(1-v^{2}\right) \Delta W_{e, e f f}+f\left(n_{i}\right) \Delta W_{p, e f f}\right]
$$

In this formulation, the effects of crack closure are inherently considered, since the energy densities are computed considering only the part of the loop where the crack stays open $[8,10]$. Crack opening levels are calculated considering the set of equations originally proposed by Newman [12]. Experimental campaigns $[8,10]$, showed that a conservative assessment of crack opening levels in LCF can be obtained by considering a con- straint factor, $\alpha$, equal to 1 , since significant out-of-plane constraint is less likely under general yielding [8]. The cyclic flow stress, $\sigma_{0}$, is usually assumed as the average of the cyclic yield stress and the ultimate strength [14].

For the given geometry, $\Delta J_{\text {eff }}$ can be computed as [10]:

$$
\Delta J_{e f f}=a\left[1.24 \frac{\Delta \sigma_{e f f}^{2}}{E}+\frac{1.02}{\sqrt{n_{i}}} \Delta \sigma_{e f f} \Delta \varepsilon_{p, e f f}\right]
$$

where $E$ is Young's modulus, $n^{\prime}$ is the exponent of the cyclic stress-strain curve, $\Delta \sigma_{e f f}$ and $\Delta \varepsilon_{p, e f f}$ are, respectively, the effective stress range and the effective plastic strain range.

Vormwald [10] showed that, during LCF, the crack closing stress, $\sigma_{\text {close }}$, occurs at the strain level measured at crackopening. This implies that the crack closing stress, is lower than $\sigma_{o p e n}$ and that the effective stress range should be calculated as proposed in Eq.3:

$$
\Delta \sigma_{e f f}=\sigma_{\max }-\sigma_{\text {close }}
$$

where $\sigma_{\max }$ is the stress peak value. Accordingly, $\Delta \varepsilon_{p, e f f}$ is calculated as:

$$
\Delta \varepsilon_{p, e f f}=\varepsilon_{\text {max }}-\varepsilon_{o p e n}-\frac{\Delta \sigma_{e f f}}{E}
$$

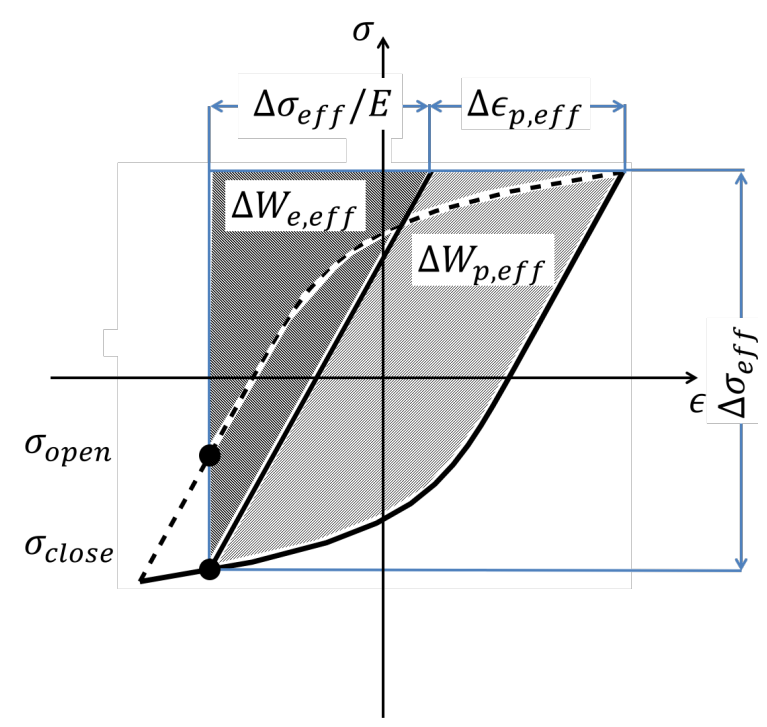

FIGURE 3. Definition of the significant part of the stress/strain cycle according to Seeger and Vormwald [10]. 


\section{RESULTS AND DISCUSSION}

Experimental results were analized with the short crack propagation model presented in the previous section: to account for material transient behavior, for each crack length, it was chosen to consider the stress and strain amplitudes measured before the test interruption, necessary to obtain the plastic replica. This allowed a more accurate description of the strain energy densities involved in crack propagation.

In Fig. 4 a, results from $\mathrm{LCF}$ testing at $500^{\circ} \mathrm{C}$ were compared with the reference crack growth curve, obtained testing $\mathrm{C}(\mathrm{T})$ specimens. It can be noted that, for both the strain amplitudes investigated, experimental data-points tend to align on the reference curve: this is due to the fact that the model can accurately describe crack closure effects, allowing an accurate description of the crack growth process.

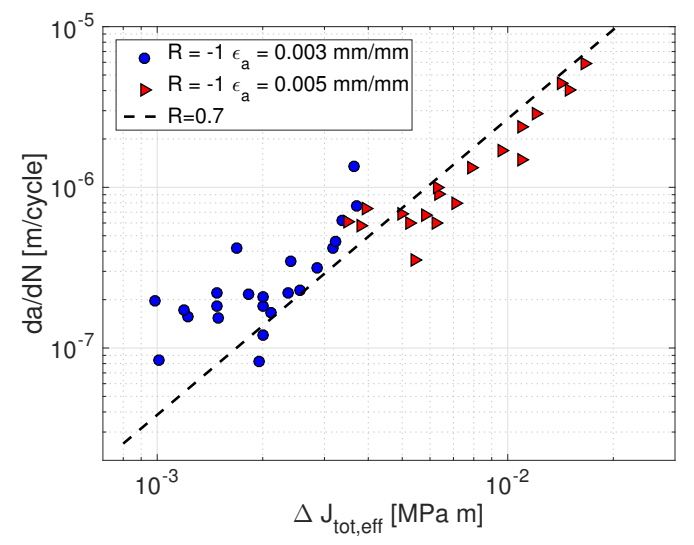

(a)

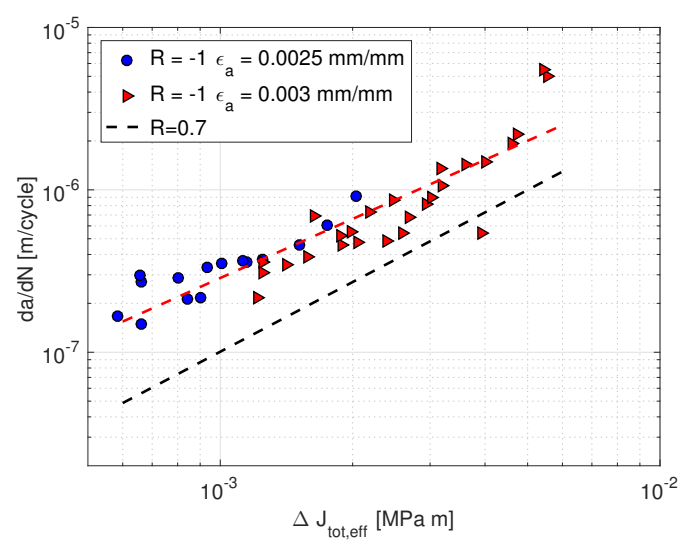

(b)

FIGURE 4. Fatigue crack growth analysis: crack growth rates vs. $\Delta J_{e f f}$, Eq. 2. a) $\mathrm{T}=500^{\circ} \mathrm{C}$ and b) $\mathrm{T}=700^{\circ} \mathrm{C}$.

An initial scatter can be observed for those tests performed at low strain amplitudes, represented by blue dots in Fig. 4: this is due to crack closure, which is a transient phenomenon and needs several cycles to fully develop $[15,16]$.

This trend is not confirmed at $700^{\circ} \mathrm{C}$, as reported in Fig. $4 \mathrm{~b}$. At an higher temperature, experimental data-points from LCF tests tend to align on a crack growth curve which is different from the reference one. The acceleration was related to a damage mechanism acting at the crack tip, as reported in Fig. 5, in which it can be noted that there are damaged regions ahead of crack tip, even before crack propagation. This micro-cracking phenomenon is similar to the one observed in a previous study $[17,18]$, in which a ferritic-martensitic steel behavior was studied at temperatures ranging from $350^{\circ} \mathrm{C}$ and $500^{\circ} \mathrm{C}$.

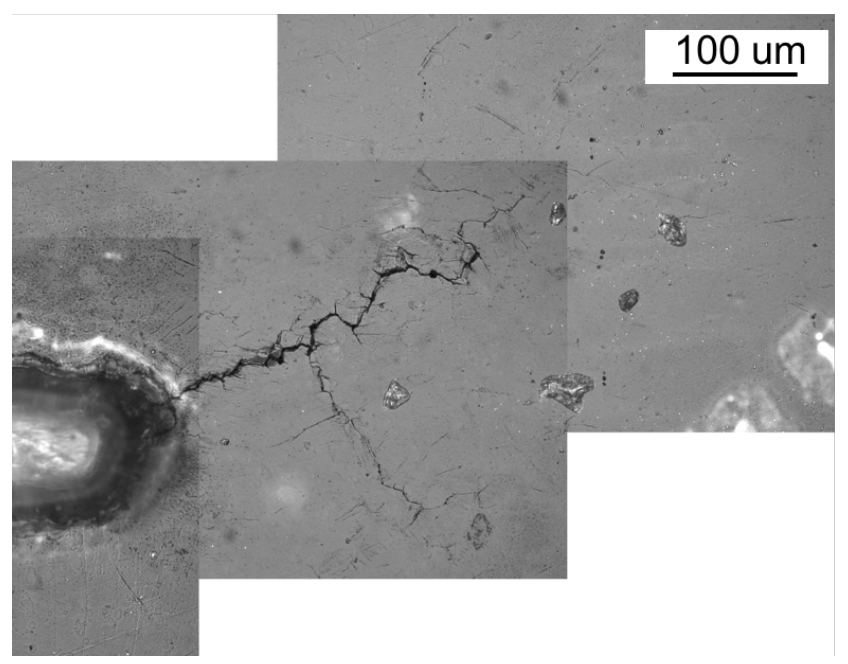

FIGURE 5. Fracture surface at $500^{\circ} \mathrm{C}$. Magnification of the damaged area around crack tip.

Summarizing results on Haynes 230, an average crack growth rate increment, $s f$, could be expressed as [13]:

$$
s f=\frac{(d a / d N)_{\exp }}{(d a / d N)_{R=0.7}}
$$

where $d a / d N_{\text {exp }}$ is the crack growth rate from LCF testing and $d a / d N_{R=0.7}$ is the growth obtained from $\mathrm{C}(\mathrm{T})$ testing at $\mathrm{R}$ $=0.7$. In particular experimental data were fitted with a power law (i.e. $d a / d N=c \cdot \Delta J^{m}$ ) and the $s f$ factor was evaluated on the interpolating curve at the mean value of $\Delta J_{\text {eff }}$ range. The $s f$ factor is shown in Fig. 6, where it is clear that the enhanced growth rate can be neglected for temperatures below $500^{\circ} \mathrm{C}$ (the scatter at room temperature was taken from data reported in [17, 18]). 


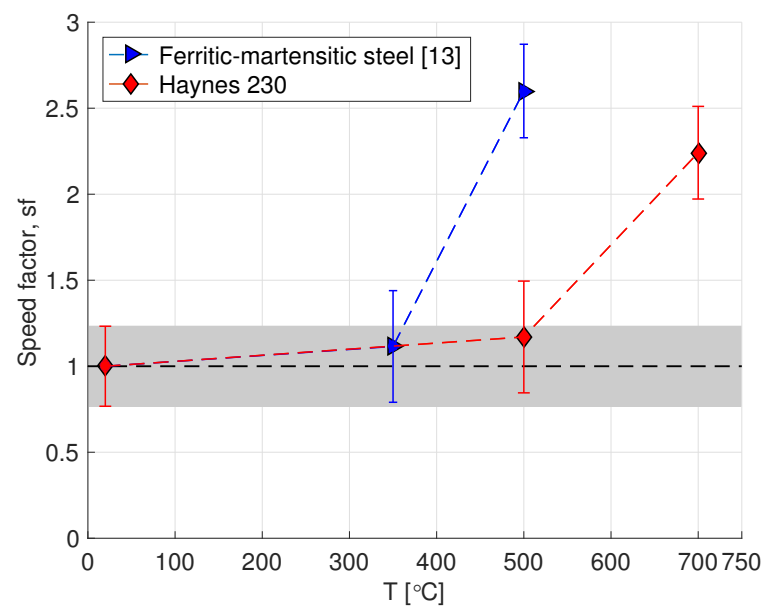

FIGURE 6. Speed increment factor. Crack growth rate acceleration against testing temperature together with $90 \%$ scatter band (5-95\% percentiles) and comparison with results from a ferritic-martensitic steel [13].

The meaning of this speed factor is that, for a correct life estimation based onto $\Delta J_{\text {eff }}$, the growth rate effective curve (the $d a / d N-\Delta J_{e f f}$ curve) should be multiplied by $s f$. The same increment is present even adopting different $\Delta J_{\text {eff }}$ models, such as the formulations by McClung and Sehitoglu $[8,9]$ and Zerbst $[6,7]$. Experimental results are compared to those of a ferriticmartensitic [13], represented in Fig. 6b, in which it can be noted that the acceleration is still presentin the experiments, but it appears at lower temperatures.

\section{CONCLUSIONS}

An experimental campaign was developed to evaluate short crack propagation in Haynes 230 specimens in presence of plastic strains: experiments in the low cycle fatigue regime were performed at 500 and $700{ }^{\circ} \mathrm{C}$ under fully reversed straining conditions. Results were compared to those obtained from long crack propagation, in terms of crack growth rates vs $\Delta J_{e f f}$, the effective J-integral range. It was found that crack growth curves for short and long cracks are coincident for temperatures below $500^{\circ} \mathrm{C}$, whereas a marked speed increment was observed for short crack propagation at $700{ }^{\circ} \mathrm{C}$. This result is in line with those observed in a previous study [13], in which it was observed the same speed increment on quenched and tempered steels for temperature above $350^{\circ} \mathrm{C}$.

\section{ACKNOWLEDGMENT}

The results presented in this work were obtained by Silvio Rabbolini, now employed at Exergy ORC, during the period he spent as a research associate at Politecnico di Milano, Dept. of Mechanical Engineering.

\section{REFERENCES}

[1] Muehle, E., and Ewald, J., 1990. "High-reliability steam turbine components - Material and strength calculation aspects". In High temperature materials for power engineering, Kluwer Academic Publishers.

[2] Miller, K., and Murakami, Y., 2005. "What is fatigue damage? a view point from the observation of low cycle fatigue process". International Journal of Fatigue, 27(8), pp. 9911005.

[3] Dowling, N., 1977. Cyclic Stress-Strain and Plastic Deformation Aspects of Fatigue Crack Growth. ASTM.

[4] Zezulka, P., and Polak, J., 2005. "Short crack growth and fatigue life in austenitic-ferritic duplex stainless steel". $F a$ tigue and Fracture of Engineering Materials and Structures, 28(10), pp. 923-35.

[5] Härkegård, G., Denk, J., and Stärk, K., 2005. "Growth of naturally initiated fatigue cracks in ferritic gas turbine rotor steels". International Journal of Fatigue, 27(6), pp. 715726.

[6] Zerbst, U., Madia, M., and Hellmann, D., 2012. "An analytical fracture mechanics model for estimation of s-n curves of metallic alloys containing large second phase particles". Engineering Fracture Mechanics, 82, pp. 115-134.

[7] Zerbst, U., Madia, M., Eufinger, J., and Bruder, T., 2013. "Bruchmechanisches modell zur ermittlung der schwingfestigkeit von geschweißten und nichtgeschweißten proben”. Materials Testing, 55(7-8), 2014/08/08, pp. 511-519.

[8] McClung, R., and Sehitoglu, H., 1988. "Closure behavior of small cracks under high strain fatigue histories". In $\mathrm{Me}$ chanics of FATIGUE CRACK CLOSURE, J. Newman and W. Elber, eds. ASTM, ch. 2, pp. 279-99.

[9] McClung, R., and Sehitoglu, H., 1991. "Characterization of fatigue crack growth in intermediate and large scale yielding”. Journal of Engineering Materials and Technology, 113, pp. 15-22.

[10] Vormwald, M., and Seeger, T., 1991. "The consequences of short crack closure on fatigue crack growth under variable amplitude loading". Fatigue and Fracture of Engineering Materials and Structures, 14(2/3), pp. 205-25.

[11] Radaj, D., and Vormwald, M., 2013. "Elastic-plastic fatigue crack growth". In Advanced Methods of Fatigue Assessment. Springer, pp. 391-481.

[12] Newman, J., 1981. "A crack-closure model for predicting fatigue crack growth under aircraft spectrum loading". In Methods and models for predicting fatigue crack growth under random loading, J. Chang and C. Hudson, eds. ASTM, pp. 53-84. 
[13] Rabbolini, S., Beretta, S., Foletti, S., and Riva, A., 2015. "Short crack propagation in lcf regime at room and high temperature in q \& t rotor steels". International Journal of Fatigue, 75, pp. 10-18.

[14] Vormwald, M., 1989. "Crack initiation life prediction based on fracture mechanics for short cracks". PhD thesis, Technical University Darmstadt.

[15] McEvily, A., Endo, M., and Murakami, Y., 2003. "On the area relationship and the short fatigue crack threshold". Fatigue and Fracture of Engineering Materials and Structures, 26, pp. 269-78.

[16] McClung, R., and Sehitoglu, H., 1992. "Closure and growth of fatigue cracks at notches". Journal of Engineering Materials and Technology, 114(1), pp. 1-7.

[17] Beretta, S., Rabbolini, S., and Di Bello, A., 2015. "Multiscale crack closure measurements with digital image correlation on haynes 230". Frattura ed Integrità Strutturale(33), p. 174.

[18] Beretta, S., Foletti, S., Rabbolini, S., and Sehitoglu, H., 2017. "Fatigue crack propagation in haynes 230: A comparison between single and polycrystal crack closure levels". In Solid State Phenomena, Vol. 258, Trans Tech Publ, pp. 243-248. 